\title{
IDENTIDAD DE GÉNERO Y LIBERTAD DE CULTO
}

\section{Rodolfo Barra}

Universidad Católica Argentina

rcbarra47@gmail.com

\section{Introducción}

Las disposiciones de la Ley 26743, llamada “de identidad de género", no dejan de plantear dificultades de aplicación. Una de las más serias, aunque probablemente poco frecuentes (dentro de la, supongo, poca frecuencia del "cambio de género"), es la que expresa el caso que ahora comento, resuelto por la Sala C de la Cámara Nacional Civil en los autos R., A. c/A.D.S. s/Habeas Data, C 061637, sentencia del 13 de noviembre de 2019, ${ }^{1}$ en el que se resolvió desfavorablemente para el actor una acción de habeas data del artículo 14, Ley 25326, acción por la que se perseguía la modificación del registro bautismal (católico) y de confirmación a los efectos de que en estos quedase solo constancia de su nuevo nombre y, con él, su nuevo "género" de elección.

Considero conveniente, antes de analizar las singularidades del caso, abordarlo desde la perspectiva de las vinculaciones entre el ordenamiento jurídico de la Iglesia católica y el de los Estados nacionales, como veremos seguidamente.

\section{Ordenamiento jurídico nacional y ordenamiento jurídico de la Iglesia católica}

Ya tuve ocasión de estudiar la relación entre el ordenamiento jurídico estatal y el ordenamiento jurídico de la Iglesia. ${ }^{2}$ Resumiendo mucho aquel estudio anterior, sostengo, apoyado en Romano (1945), que los Estados nacionales son "ordenamiento jurídico", esto es, organizaciones dotadas de juridicidad compleja: sujetos, sub-ordenamientos jurídicos, relaciones jurídicas entre todos ellos (intersubjetivas, comprendiendo a los sub-ordenamientos dotados de personalidad), centro de poder o gobierno, normas jurídicas creadas por el

\footnotetext{
1 Ver: https://www.pjn.gov.ar/.

2 Ver Derecho Público Canónico. La organización de la Iglesia Católica (2011, caps. I-III).
} 
centro de poder (heterónomas) y otras creadas por las relaciones jurídicas intersubjetivas (autónomas y siempre particulares), y una idea directriz que es la realización del bien común conforme a una determinada concepción nacional (cultural) de este. Así, el ordenamiento jurídico se confunde con la misma polis o comunidad políticamente organizada, considerada desde una perspectiva predominantemente jurídica (ubi societas ibi ius).

También la Iglesia católica es "ordenamiento jurídico", por su propia definición (así se otorga a sí misma la "potestad de régimen, jurisdicción o gobierno") (Código de Derecho Canónico, 1989, c. 129) ${ }^{3}$ y por el mismo derecho internacional, que reconoce en la Santa Sede a un sujeto del derecho internacional. La Santa Sede es cabeza de la Iglesia universal y de las iglesias particulares (c. 333, \& 1). El concepto de "Iglesia particular" alcanza principalmente (en lo que aquí interesa) a la "Diócesis" (c. 368), que es una "porción del pueblo de Dios" (es decir, de la Iglesia universal) de base territorial gobernada por el "Obispo diocesano" (cc. 369 y 381, \& 1). Por ser de base territorial, las diócesis coexisten con los Estados nacionales.

Ahora bien, el ordenamiento nacional (el que coincide con el Estado-nación) se integra con una pluralidad de sub-ordenamientos jurídicos dotados de autonomía parcial, nunca absoluta sino relativa, con respecto al ordenamiento nacional. No ocurre lo mismo en el caso de los ordenamientos jurídicos de subjetividad internacional, que actúan en paridad recíproca (son mayormente Estado-nación). La Iglesia católica, a través de su cabeza (el cuerpo sigue a la cabeza), es ordenamiento jurídico con subjetividad internacional (para simplicidad, "ordenamiento internacional" o "sujeto internacional"), con la característica agregada de actuar también dentro de los ordenamientos nacionales. Es decir, la mayor parte del "cuerpo" que corresponde a la "cabeza" pontificia (ordenamiento internacional) actúa dentro de los ordenamientos nacionales.

La calidad de "ordenamiento internacional" le es reconocida a la Iglesia por el artículo 75.22 de la Constitución Nacional, cuando encomienda al Congreso "[A]probar o desechar [...] los concordatos con la Santa Sede [...]" reconociendo en ellos "jerarquía superior a las leyes". De la misma manera, el artículo 146 del Código Civil y Comercial de la Nación (CCC) reconoce personalidad jurídica pública a la Iglesia católica, en paridad tanto con los Estados extranjeros y otros sujetos del derecho internacional público como con las personas públicas nacionales. Es importante la diferenciación hecha por el legislador 
civil con otros sujetos de base religiosa, a los que se les reconoce "personalidad jurídica privada" (artículo 148, e) del CCC). ${ }^{4}$

\section{La relación ordenamiento eclesiástico-ordenamientos nacionales. Los caracteres del ordenamiento eclesiástico}

La teoría de las relaciones entre los diversos ordenamientos jurídicos ocupa un lugar central en la ciencia del derecho, por lo menos para los que entendemos que el ordenamiento jurídico no es un fenómeno exclusivamente estatal, si bien en el Estado y por el Estado alcanza su plenitud y su dimensión unitaria dentro de la pluralidad admitida por la comunidad organizada.

En la relación entre los distintos Estados nacionales importa, entonces, el fenómeno de la relación entre ordenamientos que son soberanos e independientes entre sí. Esta realidad jurídica requiere de un "derecho de coordinación" ${ }^{5}$ tanto para el ámbito interno como internacional, que Boggiano (1998) denomina "derecho de las relaciones exteriores de los ordenamientos o ius inter iura", al que puede llegarse por inducción a través de "los casos" y su "realista localización" (pp. 8 y ss.).

En el caso de la relación del ordenamiento eclesiástico con los ordenamientos estatales nacionales, la situación es de una especial singularidad, sin por ello dejar de ser comprendido en el supuesto del ius inter iura.

Como ocurre con los ordenamientos integrantes del sistema internacional, el eclesiástico se encuentra frente al ordenamiento estatal en la misma condición de soberanía e independencia. Pero, a diferencia de lo que sucede en la relación entre ordenamientos estatales, el eclesiástico es, a la vez, un ordenamiento que actúa en el interior del estatal sin sometimiento al ordenamiento general, o sin el mismo tipo de sometimiento al que se encuentran obligados los ordinarios ordenamientos menores o sub-ordenamientos. ${ }^{6}$

Para comprender la especialidad de la relación ordenamiento estatal-orde-

4 Destacado agregado.

5 Este derecho es fruto de lo que Bobbio (1993) denomina "relación de coordinación" (p. 279); sobre las otras categorías que este autor identifica, ver pp. 279-282. También Boggiano (1998: pp. 8 y ss).

6 Bobbio (1993, pp. 285-292) distingue tres categorías de relaciones entre ordenamientos, según su confluencia o coincidencia sobre los ámbitos temporal, espacial y material. Si dos ordenamientos no coinciden en ninguno de estos ámbitos, no existe interferencia entre ellos y, por tanto, no hay problema de coordinación. Si coinciden en los tres, hay confusión de ordenamientos, de manera que uno desaparecería ante el otro. La cuestión de la coordinación nace cuando coinciden en dos de los tres ámbitos. Así, pueden tener en común los ámbitos espacial y material, pero no el temporal: 
namiento eclesiástico debemos partir de afirmar la originalidad -en cuanto originario o primario- del ordenamiento eclesiástico, es decir, su nacimiento fuera y de manera independiente del estatal (lo que no ocurre, naturalmente, con los sub-ordenamientos insertos en el estatal). Esto es así sin dejar de considerar - por el contrario, afirmar- al eclesiástico como ordenamiento verdaderamente jurídico, pero cuyos caracteres de tal naturaleza -es decir, caracteres jurídicos- no derivan de ningún ordenamiento estatal, sino que son originariamente propios. Por eso destaca Romano (1945, p. 95) que la juridicidad del ordenamiento eclesiástico no precisa de ningún tipo de atribución de tal cualidad por el ordenamiento estatal. El derecho matrimonial, el derecho penal, el derecho sacramental, etc., siempre como institutos del ordenamiento eclesiástico, guardan la calidad de verdaderas instituciones jurídicas, aunque no sean receptadas, o aun sean irrelevantes, para el Estado. Es derecho para los fieles, para quienes también son jurídicas, por ejemplo, las sanciones que el ordenamiento eclesiástico puede imponer en determinados casos. Lo que el Estado -por lo menos en un régimen pluralista y democrático- no puede hacer es desconocer su existencia, y mucho menos prohibirlo, ya que aun así seguiría existiendo, como lo demuestra la experiencia histórica, incluso la más reciente.

El ordenamiento eclesiástico es: 1) autónomo, porque se da sus propias normas sin depender ni someterse -salvo voluntariamente, conforme, normalmente, a los términos concordados (Código de Derecho Canónico, 1989, cfr. c. 3), o por propia remisión (por ejemplo, c. 1290 en materia de contratos)- a las normas estatales; 2) autojudiciable, ya que resuelve los conflictos entre o con sujetos sometidos a su ordenamiento con sus propios tribunales judiciales (cfr. c. 1401); 3) autosustentable, es decir, se sustenta en sí mismo y no en el ordenamiento estatal; 4) autosuficiente, ya que no requiere de ningún auxilio estatal para obtener y mantener su juridicidad. Por ello, para el eclesiástico no basta con hablar de autonomía. Esta puede ser atribuida o reconocida por el ordenamiento estatal a determinados sujetos que actúan dentro de este. Así, la reconoce a los sujetos físicos al consagrar el principio de la autonomía de la voluntad-aplicable,

tal es el caso de dos ordenamientos estatales que se suceden, con distinción prácticamente absoluta, en el tiempo, por ejemplo, como consecuencia de una revolución. Otro supuesto es cuando los dos ordenamientos tienen en común el ámbito temporal y el material, pero no el espacial, como ocurre con dos Estados contemporáneos que naturalmente tienen poder sobre las mismas materias, pero no en el mismo territorio. El tercero es cuando los dos ordenamientos coinciden en el tiempo y en el espacio, pero no en las materias. Este sería el caso de los Estados y la Iglesia, cuyas materias son diferentes: en lo temporal y en lo espiritual, respectivamente. De todas formas, existen muchas materias en particular en las que los dos ordenamientos coinciden, lo que torna a la coordinación en especialmente delicada. 
analógicamente, también a las personas jurídicas-, pero este no es autosuficiente -requiere del marco jurídico estatal-, aunque debamos afirmar sin lugar a dudas que es autosustentable ya que se funda en la dignidad de la persona humana. El ordenamiento estatal atribuye la calidad autónoma también a ciertas organizaciones de su propia creación y para servir a los fines de su propia organización estatal. Pero en este caso, entonces, la autonomía no es ni autosuficiente ni autosustentable. En estas condiciones, entre el ordenamiento eclesiástico y el estatal no existe relación de subsidiariedad en sentido propio, ya que entre ellos no se da una "relación de mayor a menor", y sus áreas de competencia son cualitativamente diversas y no comunicables. Esto no obsta, naturalmente, a que entre los dos ordenamientos exista, o deba existir, una verdadera relación de cooperación, como veremos más adelante.

En consecuencia, el ordenamiento eclesiástico es más que "autónomo”, o bien podemos decir que posee una autonomía fortificada - pero como un verdadero salto cualitativo- con aquellas dos notas de la suficiencia y la sustentabilidad.

\section{Principios que gobiernan la relación entre ambos ordenamientos}

Teniendo en cuenta las precisiones anteriores podemos comprender mejor el juego de relaciones que se produce entre los dos ordenamientos jurídicos: el estatal y el eclesiástico, tomando como "tipo" a un modelo de Estado no confesional ni tampoco "prohibicionista" (como era, por ejemplo, el soviético).

Lo primero que debemos tener en cuenta, entonces, es que ambos -los ordenamientos estatales y el de la Iglesia- son igualmente originarios, autónomos, autosuficientes y autosustentables. Se encuentran así en una relación de igualdad, con la particularidad de que el ordenamiento eclesiástico exige ser respetado, en tal condición de igualdad, por los ordenamientos estatales incluso dentro del propio ámbito de "soberanía" de estos últimos, es decir, en el mismo interior de la comunidad estatal. La igualdad debe ser predicada, entonces, tanto con una validez externa -como si fuesen ordenamientos de dos Estados- como interna, aunque en este punto no existen otras situaciones exactamente comparables.

Pero la relación de igualdad no basta. Esta debe ser complementada por el mutuo reconocimiento de la juridicidad de cada uno de los ordenamientos, reconocimiento que, al mismo tiempo, es una exigencia destinada a hacer posible la relación de igualdad. Esta no existiría de no tener, ambos ordenamientos, la cualidad de jurídicos.

Tal reconocimiento mutuo se refleja en la relación de relevancia jurídica, por 
la cual un ordenamiento se obliga a sí mismo a admitir la juridicidad-siempre originaria, autosuficiente y autosustentable- del otro, sin otro título para ello que el de su mera existencia y posibilidad de comprobación de su contenido.?

Así, la Iglesia no puede sino reconocer que sus fieles son, a la vez, súbditos de Estados concretos. No existe, ni es posible que exista, un fiel que no sea, a la vez, súbdito estatal, es decir, sometido al ordenamiento jurídico de un Estado (incluso los ciudadanos del Estado del Vaticano, que es un ordenamiento jurídico vinculado, pero diverso de la Iglesia). Asimismo, el Estado -siempre nos referimos al pluralista y democrático- no puede sino reconocer no solo sus obligaciones con relación a la Iglesia, impuestas por el derecho internacional, sino la realidad de que sus súbditos -no importa si muchos o pocos- se sientan y actúen como sujetos de otro ordenamiento, el que jurídicamente también los obliga en plenitud, sin depender -siquiera supletoriamente (como ocurre con los restantes ordenamientos internos al estatal)- del ordenamiento estatal. Tampoco esto es solo una realidad fáctica, sino especialmente jurídica, normalmente reconocida por los tratados o concordatos celebrados por la Iglesia y el Estado, ${ }^{8}$ sin perjuicio de resultar también del mismo "derecho de gentes".

7 Romano (1945, pp. 118 y ss.) destaca que la "relevancia jurídica" no debe confundirse con el otorgamiento de una "importancia de hecho", lo que sería solo una relevancia de conveniencia o de oportunidad, podemos decir, política. Para Romano, para que se presente tal "relevancia jurídica" es necesario que la existencia, el contenido o la eficacia de un ordenamiento se encuentre condicionado con respecto a otro en base a un "título jurídico". Dejando de lado las distintas especies de título que el autor enumera y que son inaplicables a nuestro caso -supremacía, presupuesto, compenetración-, para el caso de la relación entre Estados, Romano indica que el título reside en la existencia de un ordenamiento superior, como el derecho internacional, que se sobrepone a -y justifica la- relación de relevancia entre los dos ordenamientos estatales. Aunque también este principio sea aplicable a la relación Iglesia-Estados, pensamos que no es suficiente. El título de la "relevancia jurídica" en la relación ordenamiento eclesiástico-ordenamientos estatales debe encontrarse en un lugar diverso, en definitiva, en la existencia misma de la Iglesia como institución supranacional, con fines diversos a los de los Estados. Es decir, la Iglesia -a través de la Santa Sede- es un sujeto no estatal del derecho internacional, con una actuación supraestatal y supranacional cuyo ordenamiento es jurídicamente relevante, originario e igualitario al de los Estados, tanto en el ámbito interno o nacional -donde, por aquellas notas, no puede ser equiparado a los ordenamientos menores que existen dentro del ordenamiento inclusivo general- de cada uno de ellos como en el campo de sus relaciones jurídicas de ordenamiento general a ordenamiento general.

8 Sobre los orígenes históricos y su evolución hasta la actualidad de la práctica concordataria, y sobre el tema en general, ver Busso (2000, cap. VI). 


\section{El caso argentino}

A pesar de la extrema parquedad del acuerdo celebrado el 10 de octubre de 1966 entre la Santa Sede y la República Argentina, el ordenamiento argentino contiene normas de la máxima jerarquía (en este caso, unilaterales) que garantizan la correcta relación entre ambos ordenamientos. Así, en el régimen constitucional federal argentino, las normas fundamentales se encuentran en el juego armónico de los artículos 2, 14 y 16 de la Constitución Nacional. El primero de ellos afirma que "El Gobierno federal sostiene el culto católico apostólico romano", mientras que el segundo, en lo que nos interesa, garantiza el derecho de "todos los habitantes de la Nación" - con lo cual la norma es vinculante para las provincias y municipios $-{ }^{9}$ a "profesar libremente su culto", además de "asociarse con fines útiles". El artículo 16 complementa estas garantías al consagrar la absoluta igualdad ante la ley de todos los habitantes de la nación.

Así, dentro de un régimen de plena libertad de culto, que supone la actuación asociada institucional para profesarlo y difundirlo, ${ }^{10}$ la Iglesia recibe una situación particularizada (que no es lo mismo que "privilegiada"), en la medida en que ella profesa y difunde el culto sostenido por el Gobierno federal, aunque esta declaración constitucional debe interpretarse de manera armónica con los derechos a la libertad de culto y al trato igualitario y no discriminatorio de los artículos 14 , 16 y 18 (debido proceso sustantivo), respectivamente, de la Constitución. También esto puede expresarse de otra manera complementaria: el Gobierno federal "sostiene" 11 el culto católico sin afectar la libertad religiosa de los habitantes de la nación, de manera que tal sostenimiento o apoyo encuentra su límite en la libertad de los demás. Desde otro punto de vista, el juego armónico de aquellas normas constitucionales establece que el sostenimiento del culto católico por parte del Gobierno federal no puede afectar la libertad de la Iglesia ni la libertad de los católicos, lo que prohíbe cualquier actitud de carácter "regalista".

9 Cfr. artículo 5 de la Constitución Nacional.

10 Esto último tiene como complementos necesarios los derechos de publicar las ideas "por la prensa" (se entiende que a través de cualquier medio apto para la difusión de las ideas) sin censura previa y el de "enseñar y aprender". Obviamente, todos estos derechos deben ejercerse "conforme con las leyes que reglamenten su ejercicio", como dispone el artículo 14 de la Constitución Nacional, reglamentación que debe atender a la protección del "orden y a la moral pública" y de los derechos de terceros (artículo 19), aunque sin alterar la sustancia del derecho (cfr. artículo 28).

11 "Sostener", como "sustentar", indica tanto la acción de defender o "mantener firme" una proposición o idea como también "auxiliar" - de cualquier forma- o asistir a la manutención de alguien. Aun cuando en el debate constituyente se concluyó en que la expresión se refería al sustento económico, el texto constitucional no precisa el sentido de la palabra, con lo cual cabe entender que la utiliza en forma amplia. 
El culto "católico apostólico romano" al que se refiere el artículo 2 de la Constitución argentina no es otro que el que le otorga sentido y fundamento a la Iglesia como institución, es su "idea rectora".

No se puede sostener la "idea rectora" sin sustentar, a la vez, los restantes elementos organizativos que la misma idea rectora ha desarrollado. El mismo "culto católico" exige la existencia de la Iglesia, de su constitución jerárquica, de su organización y de su conformación como ordenamiento. No puede "sostenerse" el culto católico sin reconocer las notas de la juridicidad, originalidad, autosuficiencia y autosustentabilidad del ordenamiento jurídico eclesiástico. Tampoco puede darse tal sostenimiento si no se reconoce al mismo tiempo el estatus jurídico de "fiel" y, por tanto, el estatuto jurídico de la Iglesia-institución y de los fieles dentro del mismo ordenamiento eclesiástico, estatuto jurídico que no puede sino ser, asimismo, calificado por las mismas notas que califican al ordenamiento de procedencia.

Se enuncian así, constitucionalmente, los principios de "relevancia jurídica" -en un sentido muy especialmente subrayado, en nuestro caso, ya que el Estado declara que el ordenamiento eclesiástico es por él sostenido, o defendido, apoyado y auxiliado, lo que sería imposible, o al menos absurdo, sin mediar el reconocimiento de tal relevancia- y de "colaboración", el que también se encuentra contenido en el término "sostiene".

En congruencia con tal principio constitucional, ya el artículo 33 del antiguo Código Civil había calificado a la Iglesia católica como "persona jurídica pública”, junto con el Estado nacional, las provincias, los municipios y las entidades autárquicas, criterio que, como hemos mencionado, se encuentra reiterado en artículo 146, c) del nuevo Código Civil y Comercial.

Así, la Iglesia es reconocida por el legislador civil como persona pública, junto con aquellas que son "estatales", a pesar de no tener esta última cualidad, también, y precisamente, porque tiene su propio ordenamiento, independiente y autónomo. Es decir, nuestra legislación reconoce la existencia y valor, con todos sus efectos jurídicos, de la Iglesia-ordenamiento. Pero, en este caso, porque posee para el ordenamiento nacional la misma razón de bien común -aunque sobre materias en general distintas- que las personas jurídicas también calificadas como públicas. 


\section{El deslinde entre ordenamientos}

También en el ordenamiento eclesiástico se encuentran normas de "reenvío" a favor de la legislación civil, como el caso del c. 1286 para los contratos de trabajo y el c. 1290 para los contratos en general, sin perjuicio de la vigencia de los concordatos y otros acuerdos con sociedades políticas por encima de las mismas normas canónicas, como lo establece el c. 3 del Código de Derecho Canónico (CIC) (1989).

El ya citado principio de "colaboración", por su parte, posee igualmente naturaleza "constitucional" para la Iglesia. ${ }^{12}$ La colaboración o cooperación entre los ordenamientos eclesiástico y laico tiene su conveniente, aunque no excluyente, expresión en los "concordatos" o convenios, sin tener una distinción sustancial con los "tratados" del derecho internacional.

Conforme a los principios que rápidamente hemos mencionado en los parágrafos anteriores, se efectiviza la adecuada relación entre los ordenamientos civiles y el eclesiástico, mediando siempre el reconocimiento de la relevancia jurídica -reiteremos, originaria, autosuficiente y autosustentable- del ordenamiento canónico. Ahora bien, ¿cómo se produce el deslinde, es decir, la decisión acerca de la aplicación de la norma pertinente en un caso concreto?

Boggiano (2001, pp. 64-66) cita, entre otros, tres criterios que se encuentran, en nuestro caso, conectados. El primero de ellos es el de las normas de primacía, cuando el propio ordenamiento, al reconocer la primacía de las normas de coordinación y colaboración contenidas en los convenios entre ordenamientos "soberanos", también reconoce la primacía de las normas a las que tales convenios reenvian. Estas normas, dice Boggiano (2001), "eligen el ordenamiento aplicable en caso de colisión por lo que bien pueden ser llamadas normas de colisión o de conflicto a semejanza de las normas de colisión del derecho privado" (p. 64). ${ }^{13}$ En este supuesto, para posibilitar el reenvío, debería estar expresamente identificada o elegida la norma a aplicar (la reenviada), o bien resultar de la integración del texto de la norma de reenvío, de la reenviada y de las circunstancias del caso.

Lo anterior también puede conducirnos al segundo criterio expuesto por Boggiano (2001), el de la conexión más próxima o el genuine link. Este consiste en

12 Constitución Pastoral Gaudium et spes, Concilio Vaticano II: "La comunidad política y la Iglesia son independientes y autónomas, cada una en su propio terreno. Ambas, sin embargo, aunque por diverso título, están al servicio de la vocación personal y social del hombre. Este servicio lo realizarán con tanta mayor eficacia, para bien de todos, cuanto más sana y mejor sea la cooperación entre ellas, habida cuenta de las circunstancias de lugar y tiempo". Ver también, no 42.

13 Énfasis en el original. 
la elección de las normas pertenecientes al ordenamiento "más próximo o con lazos más estrechos con el asunto o la causa o la relación jurídica” (p. 65). El autor lo denomina también método de "inmanentización del caso transordenamiento", ya que si "el caso trasciende a un ordenamiento y se conecta con varios, habrá que elegir el ordenamiento que guarde los vínculos o contactos más estrechos con el asunto" (p. 65).

Aunque en sí mismo independiente, el tercer criterio, el de las diversas esferas de competencias -de aplicación habitual en la relación entre los ordenamientos de integración y los integrados, v.gr., el caso del derecho comunitario europeo en su vinculación con los respectivos derechos nacionales- también puede ser un complemento del anterior. Se debe aplicar la norma perteneciente al ordenamiento con competencia específica para el caso, la que si no está determinada expresa o implícitamente o no resulta de un principio de atracción también expresamente establecido, será identificable -en definitiva, será una forma de descubrir la competencia implícita- por la conexión del caso con la norma.

\section{El Concordato de 1966 y la jurisdicción de la Iglesia}

Volviendo al caso argentino, recordemos el texto del artículo I del Concordato entre la Santa Sede y la República Argentina, del 10 de octubre de 1966 (Ley 17032):

El Estado Argentino reconoce y garantiza a la Iglesia Católica Apostólica Romana el libre y pleno ejercicio de su poder espiritual, el libre y público ejercicio de su culto, así como de su jurisdicción en el ámbito de su competencia, para la realización de sus fines específicos.

El Concordato enumera así tres "garantías" u obligaciones del Estado Argentino con relación a la Iglesia, que identifica como "poder espiritual", culto público y libre y jurisdicción. Esta enumeración no ha sido, seguramente, ocasional, ya que sustancialmente coincide con las tres potestades que el ordenamiento eclesiástico le otorga a su "centro de poder" o "gobierno", en el caso, la Santa Sede (el papa y, en ocasiones, la curia vaticana), los obispos con el papa y los obispos en sus propias diócesis. ${ }^{14}$

14 Es también así en los ordenamientos estatales. El Estado -en nuestro caso, en realidad, el Gobierno, ya que el Estado nacional es la personificación jurídica del "Gobierno federal" - ejerce la "autoridad" a través de tres órganos superiores dotados de potestad (poder) para cumplir con determinadas competencias. En el caso de la Iglesia, donde no existe la "división de poderes", el poder o potestad de 
Tales tres potestades son: la de orden o de santificar, la de magisterio y la de régimen. Cada una de estas, desde el punto de vista jurídico, habilita el ejercicio -aunque no de manera igual en cada caso- de un conjunto de competencias confiadas a oficios eclesiásticos determinados, conforme a lo regulado por el CIC. ${ }^{15}$

En el ordenamiento eclesiástico, la "potestad" tiene naturaleza especial. El fin del ordenamiento eclesiástico es la salvación de las almas, esto es, un fin sobrenatural, aunque deba comenzar a ser transitado ya en el tiempo, todo lo cual es voluntariamente aceptado por los fieles como, precisamente, materia de fe. Así, mientras en el ordenamiento estatal el poder y su atributo propio -la potestad- son políticos, e.d., para el gobierno de la polis o comunidad política, en el ordenamiento eclesiástico el poder y la potestad que le es inherente son "sagrados", en cuanto dedicados a unir a las criaturas con el Creador. La potestad en la Iglesia es "sacra", porque la misma Iglesia es sacramento que expresa sensible y eficazmente la gracia de Dios para la salud de las almas (salus animarum), siempre, cabe insistir, quien voluntariamente acepte someterse a tal ordenamiento.

La potestad d la Iglesia es esencialmente una -la de santificar-, aunque también se exprese en tres distinguibles por su fin inmediato (el fin mediato es siempre la salus animarum): como vimos, la potestad de orden, la de magisterio y la de jurisdicción o gobierno. Estas tres potestades son, cabe reiterar, "sacras", pues han sido establecidas por el Fundador, Jesús, para "apacentar el Pueblo de Dios". Las "tres potestades" se encuentran, sin confundirse, íntimamente ligadas. Así, aunque conceptual y materialmente deban distinguirse, todas emanan del propio "sacro orden" instituido por Cristo.

Por consiguiente, existe una correlación necesaria entre el "orden” y el "régimen", como también el "magisterio", sin perjuicio de la distinción que las tres admiten como potencias que se especifican por sus actos y los objetos propios de tales actos.

Así, entonces, "la gestión gubernamental" propiamente dicha en la Iglesia es ejercida mediante la potestad de régimen, sin perjuicio de que el magisterio es, a la vez que transmisión de la verdad, conducción (se "apacenta" el Pueblo conduciéndolo hacia el Reino). El gobierno y el magisterio, por su parte, son actuaciones propias, en sentido pleno, de la potestad de orden. Precisamente,

santificar (salud de las almas) se ejerce mediante tres actividades sustanciales (las "potestades sacras").

Cfr. cc. 129 y 145 para la "potestad de régimen". 
solo los dotados de potestad de orden -los "ordenados" - pueden ejercer plenamente, aunque según el oficio y órgano de que se trate, la potestad de régimen ${ }^{16}$ y la potestad magisterial.

El Concordato garantiza, antes que nada, el ejercicio, por la Iglesia, de una potestad central para su autonomía, que reside en el ejercicio de la potestad ministerial sacerdotal por quienes han recibido el denominado "orden sagrado".

\section{La potestad de orden}

El acceso al orden clerical, al sacerdocio ministerial, se realiza a través del sacramento del orden, tal como lo declara y, "por institución divina", establece el c. 1008. Esta es una definición de gran importancia para el ordenamiento, ya que este, como sabemos, tiene una finalidad salvífica que se expresa fundamentalmente a través de la palabra, la liturgia y los sacramentos, es decir, una potestad espiritual ejercida, en sentido amplio, a través del culto, ambos aspectos de una misma realidad garantizados por el Concordato.

En derredor a la potestad de orden o sacra gira la totalidad del ordenamiento de la Iglesia, esto es, en torno a los sacramentos: por el bautismo, que introduce al sujeto en la Iglesia; por la confirmación, que lo ratifica en la fe adulta; por el matrimonio, que consagra el amor entre el hombre y la mujer y los hace continuadores de la obra de la Creación; por la eucaristía, que realiza la participación de los fieles en el misterio salvífico de la pasión, muerte y resurrección de Cristo; por la penitencia y reconciliación, que reintegra en la comunidad; por la unción de los enfermos, que nos ayuda a sobrellevar los dolores de la enfermedad y nos prepara para la vida eterna; y, finalmente, por el orden sagrado, que continúa, ministerialmente, el sacerdocio sagrado de Cristo. ${ }^{17}$

Las condiciones -subjetivas y objetivas- de acceso a los sacramentos se encuentran reguladas por el derecho propio de la Iglesia. Teniendo en cuenta que la vida sacramental es la esencia del culto y del ordenamiento eclesiástico, la li-

\section{Cfr. c. 129.}

17 De estos siete sacramentos, cinco son calificados como "sacramentos al servicio de la comunidad" por el Capítulo Tercero del Catecismo de la Iglesia Católica (Conferencia Episcopal Argentina, 1998, n 1533). El bautismo, la confirmación y la eucaristía son los sacramentos de la iniciación cristiana. Fundamentan la vocación común de todos los discípulos de Cristo, que es vocación a la santidad y a la misión de evangelizar el mundo. Confieren las gracias necesarias para vivir según el espíritu en esta vida de peregrinos en marcha hacia la patria ( $\left.n^{\circ} 1534\right)$. Otros dos sacramentos, el orden y el matrimonio, están ordenados a la salvación de los demás. Contribuyen ciertamente a la propia salvación, pero esto lo hacen mediante el servicio que prestan a los demás. Confieren una misión particular en la Iglesia y sirven a la edificación del Pueblo de Dios". 
bertad de regular y administrar los sacramentos es central tanto para el ejercicio del culto como para la autonomía "ordinamental", garantizadas, cabe reiterar, por el Concordato y por el mismo artículo 2 de la Constitución Nacional.

\section{La potestad magisterial}

La Iglesia, depositaria de la fe por expresa encomienda de su Fundador, "[...] tiene el deber y el derecho originario, independiente de cualquier poder humano, de predicar el Evangelio a todas las gentes [...]" (c. 747). Enseñar y difundir el Evangelio es una misión connatural de la Iglesia -es el fin propio de la organización, que incluye la definición de su doctrina, el que se encuentra directamente enderezado a la santificación o salud de las almas-, de manera que sin ella no existiría como organización, como ordenamiento propio e independiente de los ordenamientos civiles. Esta independencia es exigida como condición misma de libertad para la Iglesia, como lo plantea la norma arriba citada.

Pero aquella misión de la Iglesia no es lo mismo que la "potestad de magisterio", aunque esta última se encuentre sustentada en aquella. La misión evangelizadora de la Iglesia -que supone la difusión y enseñanza de la palabra de Dios y la administración de los medios salvíficos- se ejerce con relación a "todas las gentes", dice el c. 747. Aquella es una obligación de todos los fieles, ${ }^{18}$ incluyendo, naturalmente, a los laicos. ${ }^{19}$

En cambio, la potestad de magisterio, en sentido estricto, se ejerce con relación a los fieles, ya que supone una situación jurídica de derecho-deber ${ }^{20}$ que solo puede predicarse en la relación autoridad-súbdito, entre los dotados por el ordenamiento de tal autoridad y quienes se encuentran obligados a recibir la enseñanza, a acatarla y, también, el derecho a exigirla en las condiciones fijadas por el mismo ordenamiento.

La "magisterial" es potestad en tanto que es un acto propio del ejercicio de la autoridad, del poder de conducción de la organización, y, por tanto, de acatamiento obligatorio por parte de todos sus miembros (clérigos y laicos, es decir, todos los fieles).

En un sentido propio, la potestad magisterial se encuentra confiada al papa

18 Cfr. c. 211.

19 Cfr. c. 225.1.

20 Cfr. cc. 212.1 y 213. 
y al Colegio Episcopal en comunión con el pontífice ${ }^{21}$ tanto en lo que respecta al magisterio extraordinario o infalible (ver nota anterior) como al magisterio ordinario, que también obliga a los fieles a "[...] prestar un asentimiento religioso del entendimiento y de la voluntad, sin que llegue a ser de fe [...]", como lo dispone el c. 752. Siempre dentro del magisterio ordinario, también cabe el mismo tipo de "asentimiento religioso" a las enseñanzas de los obispos "en comunión con la Cabeza y los miembros del Colegio", aunque actúen individualmente o en conjunto en Conferencias Episcopales o Concilios particulares, es decir, fuera del Colegio Episcopal (c. 753). También el libre ejercicio de la potestad magisterial es, entonces, requisito del libre ejercicio de la autoridad en la Iglesia.

\section{La potestad de "régimen, jurisdicción o gobierno"}

Sin perjuicio de la íntima unidad de las tres "potestades sacras", la denominada “potestad de régimen” es la que expresa más específicamente el fenómeno del gobierno en la Iglesia, en una dimensión funcional semejante a la de los ordenamientos civiles y en la que se actualiza la conducción del conjunto a través de las tres actividades de creación jurídica: legislar, administrar y juzgar.

En el ordenamiento eclesiástico, la potestad de régimen compete siempre al "orden", a los "sellados con el orden sagrado", 22 es decir, al conjunto de personas de la organización que, salvo excepciones, dedican la totalidad de su actividad al servicio de esta y cuya principal misión es ayudar a la salud de las almas, mediante la enseñanza de la verdad revelada, la administración de los sacramentos y la liturgia -es decir, las otras dos potestades sacras-, para lo cual la jurisdicción o gobierno es siempre instrumental, pero, a la vez, indispensable.

Esta potestad se encuentra en el núcleo de la consideración de la Iglesia como ordenamiento, el que no puede existir sin un "centro de poder". Este, mediante la acción de gobierno -que supone la concepción doctrinaria previa, que en la Iglesia es el denominado "depósito de la revelación" y el magisterio, y la conducción posterior - emite órdenes de cumplimiento obligatorio y, por tanto, de naturaleza normativa, con fuerza vinculante - por principio general- en el fuero externo y -por excepción- en el fuero interno. Se trata siempre de una potestad plena de gobierno, por lo que encierra en sí misma las tres competencias materiales con relación a la norma jurídica: legislativa, ejecutiva y judicial. Es

21 Constitución Lumen Gentium, n 25, Concilio Vaticano II.

22 Cfr., c. 129, \& 1. 
decir, la libertad de jurisdicción garantizada a la Iglesia por el Concordato y por el artículo 2 de la Constitución Nacional (sin ella no hay culto católico) supone el propio y exclusivo ejercicio de las funciones legislativa, ejecutiva y judicial, con los medios aportados por el mismo ordenamiento.

A diferencia de lo que ocurre en las sociedades civiles, la potestad de régimen o gobierno en la Iglesia se encuentra divinamente fundada y conferida al Sumo Pontífice y no al pueblo o conjunto de fieles. Es al papa a quien le compete distribuirla, coordinarla, delimitarla y revocarla. Así lo prescribe el c. 331:

El Obispo de la Iglesia Romana, en quien permanece la función que el Señor encomendó singularmente a Pedro, primero entre los Apóstoles, y que había de trasmitirse a sus sucesores, es cabeza del Colegio de los Obispos, Vicario de Cristo y Pastor de la Iglesia universal en la tierra; el cual, por tanto, tiene, en virtud de su función, potestad ordinaria, que es suprema, plena, inmediata y universal en la Iglesia y que puede siempre ejercer libremente.

La potestad pontificia de régimen es: ordinaria, es decir, aneja al oficio (c. 131); suprema, pues no reconoce sobre sí ninguna otra autoridad superior, y así, por ejemplo, no puede someterse al juzgamiento de tribunal alguno (c. 1404) y sus decisiones son irrecurribles, incluso ante el Concilio Ecuménico, ante cualquier otra forma de actuación del Colegio Episcopal (c. 1372 y 333, \& 3) y ante cualquier otra autoridad eclesiástica o, naturalmente, civil; plena, pues colma en sí misma toda la autoridad posible, tanto, y en cada caso, judicial, ejecutiva y legislativa; inmediata, de manera que ninguna otra autoridad puede interponerse -no existen intermediarios- entre el papa y los fieles, ordenados o no, y entre los primeros, cualquiera sea el orden. Así, el pontífice tiene potestad ordinaria no solo sobre la Iglesia universal, sino primacía de aquella potestad "sobre todas las Iglesias particulares y sobre sus agrupaciones" (c. 333, \& 1) y sobre todos los institutos religiosos. Es también libre en su ejercicio, tanto en el interior de la Iglesia como, naturalmente también, frente a cualquier poder o autoridad externa, por lo cual el poder pontificio es de una naturaleza discrecional absolutamente libre.

La potestad de régimen se asienta también y con los mismos caracteres en el Colegio Episcopal, siempre que se encuentre en comunión con el papa ("en unión con su cabeza y nunca sin esa cabeza", reza el c. 336) que así es "sujeto de la potestad suprema y plena sobre toda la Iglesia” (c. 336), y luego en los obispos individualmente en cada una de las respectivas Iglesias particulares confiadas a su cuidado. Pero aún la autoridad colegial se encuentra condicionada a la volun- 
tad del pontífice, a quien le corresponde exclusivamente convocar al Colegio, presidirlo (aunque puede delegar esta función), trasladarlo, suspenderlo o disolverlo, aprobar sus decretos, determinar las cuestiones de competencia conciliar y aprobar otras que sean agregadas por los padres conciliares (c. 338, \&\& 1 y 2 ).

La potestad de régimen posee el contenido que de manera propia le corresponde al oficio eclesiástico de que se trate, lo que exige la existencia previa de la "misión apostólica o canónica" o, en su caso, para los párrocos en la medida de su competencia, de la previa "incardinación" (ambas, misión e incardinación, instituciones propias del derecho canónico).

\section{La jurisprudencia de la Corte Suprema de Justicia de la Nación}

Nuestra Corte Suprema de Justicia tuvo ocasión de aplicar el ya citado acuerdo de 1966, con evidente empleo de los principios mencionados.

En Juan Lastra c/Obispado de Venado Tuerto, ${ }^{23}$ el Tribunal se enfrentó con un caso de embargo, con orden de subasta, de un inmueble de propiedad de la diócesis demandada, donde funcionaba la sede y vivienda del obispo diocesano. La Corte advirtió que se trataba de un bien encuadrado en la definición "de bienes temporales" instrumentales para alcanzar la satisfacción de los fines propios de la Iglesia, que resulta del c. 1254, \& 2 del $\mathrm{CIC}^{24}$ y concordantes, entre ellos, la caracterización de "bienes eclesiásticos" establecida por el c. 1257, \& 1. Esta es la conexión más próxima entre la norma y el caso, posible de aplicación en virtud de la relevancia jurídica reconocida al ordenamiento eclesiástico por el artículo I del Concordato. "Tal reconocimiento de jurisdicción -sostuvo la Corte- implica la más plena referencia al ordenamiento jurídico canónico para regir los bienes de la Iglesia destinados a la consecución de sus fines [...]" (considerando $4^{\circ}$ ), sin perjuicio de la aplicación del entonces artículo 2345 del Código Civil. Y así concluye el Tribunal que

en tales condiciones, perteneciendo el bien embargado a la diócesis demandada, toda interferencia jurisdiccional sobre su disponibilidad solo puede decretarse o reconocerse en la República de conformidad con el ordenamiento canónico en virtud de sus disposiciones aplicables, a las que reenvía el derecho argentino (cánones 1291 a 1293 y 1295, en relación con los cánones 124.1, 127.1 y 127.2 del Código antes citado). (considerando $6^{\circ}$ )

23 Fallos: 314:1324, del 22 de octubre de 1991.

24 Cfr. considerando $5^{\circ}$. 
Esta es una clara aplicación del principio o criterio de "la esfera de competencia”, en este caso, la correspondiente al ordenamiento eclesiástico.

En la causa Antonio Rybar c/Rómulo García ${ }^{25}$ se llevó a conocimiento de la Corte una impugnación de constitucionalidad contra el celibato sacerdotal. Si bien la mayoría del Tribunal consideró que se trataba de una cuestión "no justiciable" por tratarse de una materia propia de la Iglesia católica en el ámbito de su competencia, es decir, una reafirmación de la doctrina "Lastra", los votos concurrentes de Boggiano y Barra, aun coincidiendo en la no justiciabilidad de las sanciones que habían sido impuestas por la autoridad eclesiástica al sacerdote que había contrariado la regla del celibato, amplió las consideraciones de "Lastra", indicando que el "reconocimiento de jurisdicción" (relevancia jurídica) hecho por el Concordato de 1966 "implica la más plena referencia al ordenamiento jurídico canónico para regir las faltas y sanciones disciplinarias previstas en el mismo [...." (considerando $3^{\circ}$ ). En los considerandos $4^{\circ}$ y $5^{\circ}$, los jueces citados desestimaron la alegación del impugnante en el sentido de que la regla del celibato era contraria a garantías constitucionales y legales, ya que las normas invocadas en tal sentido no representaban la "conexión más próxima al caso", habida cuenta del sometimiento voluntario que el impugnante había efectuado con relación al ordenamiento eclesiástico al consentir su ordenación sacerdotal (competencia), y considerando también que el celibato sacerdotal de ninguna manera es contrario al orden público argentino, lo que por lo demás sería imposible de invocar ante la clara y enfática disposición del artículo 2 de la Constitución Nacional.

\section{El caso R.A.}

En R.A., la parte actora había sido bautizada como varón, conforme con su sexo biológico. Con el tiempo, la actora cambió de género y nombre, mutando al femenino. Con deseo de ser madrina (femenino) de la hija de una amiga, solicitó la modificación de los registros de bautismo y confirmación, que son llevados en jurisdicción de la Iglesia conforme con los cc. 877 y 895, respectivamente, del CIC. La petición fue denegada, lo que llevó a la actora a demandar por vía de la acción de habeas data (artículo 14 de la Ley 25326).

La sentencia de la Sala C de la Cámara Civil, confirmatoria de la decisión de Primera Instancia, hace una correcta aplicación de los principios arriba desarrollados, especialmente de la jurisprudencia de la Corte Suprema, que también

25 Fallos: 315:1294, del 16 de junio de 1992. 
hemos ya citado. Así, concluye resolviendo la no "justiciabilidad", en sede civil, de la cuestión, la que, podemos precisar, por tratarse de una materia sacramental de la Iglesia católica, debe resolverse por las normas de ese ordenamiento y, en su caso, por los propios tribunales eclesiásticos, lo que, por encontrase en juego el libre ejercicio de la potestad de orden y la potestad de jurisdicción, fue garantizado por el Concordato de 1966.

La anotación de la administración de los sacramentos del bautismo y de la confirmación en los registros mandados por el CIC es importante porque ambos habilitan la recepción de otros sacramentos, sin perjuicio de otras hipótesis previstas por el mismo CIC. Obviamente, la anotación indica el sexo biológico del receptor del sacramento (el derecho de la Iglesia se guía por el principio de la identidad de sexo, no de "género", sin perjuicio por el respeto y amor por todos los seres humanos), teniendo en cuenta que aquel es el único admitido en la Iglesia con valor de verdad revelada, es decir, de contenido de la misma fe, cuya libre profesión garantiza el Concordato: "Y creó Dios al hombre a su imagen, a imagen de Dios lo creó; varón y hembra los creó" (Génesis 1.27).

El sexo del fiel -es decir, la identidad de sexo- es uno de los requisitos que el ordenamiento eclesiástico considera para la recepción de importantes sacramentos: el del "orden sagrado" y el del "matrimonio".

Con respecto al primero de ellos, el c. 1024 prescribe: "Solo el varón bautizado recibe válidamente la sagrada ordenación", esto es, el "varón" conforme fue creado por Dios y en las condiciones en las que fue bautizado, en el caso, como varón. El matrimonio, por su parte, también exige la "identidad de sexo" (es decir, la identificación del sexo biológico, sin consideración del denominado "género"): "La alianza matrimonial, por la que el varón y la mujer constituyen entre sí [...]”, reza el c. 1055 , \& 1, principio reiterado en el c. 1057 , \& 2 . El sacramento del matrimonio no puede celebrarse entre personas del mismo sexo, bajo pena de nulidad absoluta e insanable, haya sido este vicio conocido o no por los contrayentes y/o del ministro celebrante.

Si se modificasen los registros de bautismo y confirmación, se estaría modificando también la identidad sexual de la persona y, por tanto, alterando los requisitos para la válida administración de otros sacramentos, por ejemplo, admitir la ordenación sacerdotal de una persona sexualmente mujer devenida en, según el género adoptado, varón, condición que ni siquiera sería definitiva conforme con la Ley 26743 (artículo 8), la que admite renovadas opciones. Nótese que de esta manera una persona sexualmente mujer, pero varón según su género (en los términos de la Ley 26743), podría ser ordenada sacerdote, para, incluso, después 
retornar a la condición original de mujer, continuando en su calidad de sacerdote, de manera que en virtud de una ley del Estado y de la decisión de un magistrado del mismo Estado se estaría alterando el ejercicio del poder espiritual, libre ejercicio del culto y la jurisdicción de la Iglesia, en contradicción con la garantía pactada en el Concordato de 1966. También se conduciría así a la modificación de los requisitos de validez del sacramento matrimonial con efectos importantes, entre otros, sobre su régimen de nulidades, también teniendo en cuenta la mutabilidad legal de la opción por género. También se estarían alterando las condiciones para la admisibilidad de los institutos de vida consagrada (por ejemplo, las denominadas órdenes religiosas, masculinas y femeninas), reguladas por sus propios estatutos aprobados por las autoridades eclesiásticas.

\section{La aplicabilidad de la Ley 26743 al caso}

La pretensión de la actora en R.A. no podía ser sino rechazada, en tanto que la aplicación de la Ley 26743 al caso hubiese sido manifiestamente inconstitucional. Se presentó en R.A., como en el legendario Marbury, la cuestión de la aplicación de dos normas contradictorias: las del Concordato con su necesaria remisión al ordenamiento de la Iglesia, en especial el CIC, y el régimen de la ley citada, en cuanto obliga a tomar en consideración la última opción de género hecha por el interesado. El artículo 75, inciso 22 de la Constitución Nacional prescribe expresamente la supremacía jerárquica del Concordato sobre cualquier norma, incluso legal, del ordenamiento nacional.

No podría sostenerse una suerte de "inconstitucionalidad sobreviniente" del Concordato de cara a la Ley 26743. La "Convención de Viena sobre el derecho de los Tratados", ratificada por Ley 19865 y, por tanto, también de jerarquía superior a la Ley 26743, establece en su artículo 27: "Una parte no podrá invocar las disposiciones de derecho interno como justificación del incumplimiento de un tratado. Esta norma se entenderá sin perjuicio de lo dispuesto en el artículo 46". Es decir, ninguna norma, ni siquiera constitucional, puede impedir o justificar la no aplicación de un tratado, salvo el supuesto del citado artículo 46: cuando el Estado se obliga, en el tratado, en manifiesta violación de "una norma de importancia fundamental de su derecho interno". Discutir si la Ley 26743 es de importancia fundamental para nuestro derecho, aun sin ser de jerarquía constitucional, sería ocioso en tanto no existía a la fecha de celebración del Concordato y, fundamentalmente, no ha conducido a que el Estado argentino pretendiese la modificación o denuncia del mismo Concordato. Es 
decir, el Estado argentino ha interpretado que ambas normas pueden coexistir, en tanto no se pretenda la aplicación de la ley en contradicción con las obligaciones asumidas por la República en el citado Concordato.

Por otra parte, el texto mismo de la ley de "identidad de género" indica que ella impone obligaciones a las autoridades nacionales (Gobierno federal y provinciales). La "oponibilidad a terceros" que predica el artículo 7, sin perjuicio de no ser invocable al caso por las razones expuestas hasta el presente, se encuentra limitada por la misma ley, que expresamente dispone: "La rectificación registral no alterará la titularidad de los derechos y obligaciones que pudieran corresponder a la persona con anterioridad a la inscripción del cambio registral [...]", es decir, el cambio registral no puede alterar los términos de la relación jurídica preexistente al cambio, en el caso, la relación jurídica que hace que la actora en R.A. sea "persona en la Iglesia" (cc. 96 y 849) en las condiciones en las que recibió su bautismo, sacramento indeleble de iniciación y condicionante de los posteriores sacramentos.

\section{Conclusión}

Quizás el caso R.A., en su trasfondo, no importe tanto una disputa jurídica sino un claro intento de imponer, aun en el seno de la Iglesia y desde fuera de ella, una determinada agenda ideológica, la denominada "agenda de género", o imposición en todos los ámbitos de la vida social de la prohibición de diferenciación e identificación personal en razón del sexo natural para ser suplantada por una postura individual de elección del "género", que puede ser masculino, femenino u otros (i?) diversos del sexo biológico. Es parte - una batalla- de la denominada - por el fallecido juez de la Corte Suprema de Justicia estadounidense Antonio Scalia- "guerra cultural", mediante la cual el "progresismo" intenta imponer autoritariamente sus valores con vocación totalizadora.

Claro que esto tampoco quiere decir que sea "justa" la guerra contraria, de persecución y condena de quienes piensen distinto o se sientan distintos. Lo importante, por lo que sin duda vale la pena "hacer la guerra" (siempre pacífica), es la defensa de la propia esfera de libertad de individuos y sectores, de la libertad de elegir, que también implica la libertad de elegir una determinada confesión religiosa (para los católicos, en razón de la fe, ayudada por la Gracia de Dios) y así someterse voluntariamente a sus reglas.

Es de esperar que los sostenedores de la ideología de género acepten respetar la libertad de culto consagrada por el artículo 14 de la Constitución Nacional. 


\section{Bibliografía}

Bobbio, N. (1993). Teoria Generale del Diritto. Giappichelli.

Boggiano, A. (1998). Derecho Internacional público y privado y Derecho del MERCOSUR. La Ley.

Boggiano, A. (2001). Derecho Internacional. Derecho de las relaciones entre ordenamientos jurídicos y derechos humanos. La Ley.

Busso, A. D. (2000). La Iglesia y la Comunidad Política. Facultad de Derecho Canónico de la Universidad Católica Argentina, EDUCA.

Catecismo de la Iglesia Católica. (1998). Conferencia Episcopal Argentina.

Código de Derecho Canónico. (1989). Biblioteca de Autores Cristianos.

Derecho Público Canónico. La organización de la Iglesia Católica. (2011). (Tomo I). Marcial Pons.

Romano, S. (1945). L'Ordinamento Giuridico (2a ed.). Sansoni. 
